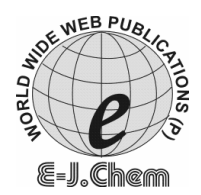

http://www.e-journals.net
ISSN: 0973-4945; CODEN ECJHAO

E-Journal of Chemistry

Vol. 5, No.4, pp. 844-852, October 2008

\title{
Studies on the Removal of Rhodamine B and Malachite Green from Aqueous Solutions by Activated Carbon
}

\author{
A. EDWIN VASU \\ Post Graduate and Research Department of Chemistry, \\ St. Joseph's College (Autonomous), Tiruchirappalli-620 002, India. \\ vasusjc@yahoo.co.in
}

Received 9 February 2008; Accepted 5 April 2008

\begin{abstract}
Activated carbon prepared from tamarind fruit shells by direct carbonization was used for the removal of rhodamine B and malachite green dyes from aqueous solutions. Adsorption studies were performed by varying such parameters as dye concentration, $\mathrm{pH}$ of the dye solution, time and temperature. The equilibrium adsorption data obtained were used to calculate the Freundlich, Langmuir and Redlich-Peterson isotherm parameters. Increase in $\mathrm{pH}$ of the solution $\mathrm{pH}$ resulted in increased adsorption of both the dyes. Kinetic studies indicate that the pseudo-second order model can be used for describing the dynamics of the sorption processes. Film diffusion of the dyes was the rate determining step at low dye concentrations while diffusion of dyes through the pores the carbon particles determined the overall uptake at high concentrations. Thermodynamic parameters of the endothermic sorptions were evaluated using van't Hoff equation. Desorption studies with acids were also performed in order to regenerate the used carbons.
\end{abstract}

Keywords: Activated carbon, Dye removal, Film diffusion, Particle diffusion, Desorption

\section{Introduction}

The cleaning of wastewater is one of the most serious environmental problems of the present day. Discharge of dyeing industry wastewater into natural water bodies is not desirable as the colour prevents reoxygenation in receiving waters by cutting off penetration of sunlight. This upsets the biological activities in water bodies. Most of the dyes used as colouring materials are toxic to aquatic organisms ${ }^{1}$. In addition, wastewaters from dyeing and textile industries easily produce toxic trihalomethanes when chlorinated ${ }^{2}$. 
Methods such as chemical coagulation ${ }^{3}$, ozonization ${ }^{4}$, membrane filtration ${ }^{5}$, electrolysis ${ }^{6}$, oxidation $^{7}$ and bio-degradation ${ }^{8}$ have been widely used for the removal of dyes from water and wastewater. As these established technologies are often unable to adequately reduce contaminants concentrations to desired levels ${ }^{9}$ a search is on more effective and economic treatment techniques.

Adsorption is by far the most effective and non-destructive technique that is widely used for the removal of dyes from aqueous solutions. It is attractive as the adsorbed dyes can be recovered with suitable regenerating agents. To make the treatment process economic several investigators have concentrated their work on low-cost, adsorbent materials.

The present study is undertaken to evaluate the applicability of a carbon prepared from tamarind fruit shells (TFC) for the removal of rhodamine B and malachite green dyes from aqueous solutions. Malachite green (MG) is a common basic dyestuff of triphenylmethane series used for dyeing silk and wool directly and cotton mordanted with tannin. Rhodamine B is also widely used in many industries. The properties of these dyes are given in Table 1 .

Table 1. Properties of malachite green and rhodamine B

\begin{tabular}{l}
\hline \multicolumn{3}{c}{ Malachite Green } \\
Molecular formula
\end{tabular}

\section{Experimental}

\section{Adsorbent}

The activated carbon used in this study was prepared one-step pyrolysis by carbonizing tamarind fruit shells in a muffle furnace at a temperature of $600^{\circ} \mathrm{C}$ for 30 minutes. The carbon was ground and sieved to get particles of size $150-250 \mu \mathrm{m}$.

\section{Estimation of dyes}

The dyes were estimated colorimetrically by monitoring their absorption in the visible region, 555nm for $\mathrm{RB}$ and $620 \mathrm{~nm}$ for $\mathrm{MG}$, using Spectronic 20D+ spectrophotometer (Spectronic Instruments, USA). Calibration graphs were prepared (1-6mg/L for RB and $1-8 \mathrm{mg} / \mathrm{L}$ for $\mathrm{MG}$ ) and concentrations of sample aliquots were established by referring to the respective calibration graph. 


\section{Adsorption experiments}

Batch mode adsorption method was followed. For equilibrium adsorption studies, a known amount of adsorbent was equilibrated with $50 \mathrm{~mL}$ of dye solutions of desired concentrations for a predetermined period of time at a constant temperature $\left(30,45\right.$ and $\left.60^{\circ} \mathrm{C}\right)$. After the equilibration, the carbon was separated by filtration using Whatmann No.41 filter paper, the first $10 \mathrm{~mL}$ of filtrate was discarded and the remaining filtrate was analyzed for the unadsorbed dye concentration. For kinetic studies experiments were done with fixed carbon and adsorbate doses with varying contact times. $\mathrm{pH}$ variation studies were performed with adjusting the initial $\mathrm{pH}$ of the dye solutions with dil. $\mathrm{HCl}$ or dil. $\mathrm{NaOH}$ solutions.

\section{Desorption experiments}

To test the recoverability of the adsorbed dye molecules, some desorption experiments were done with water, dil. $\mathrm{HCl}$ and dil acetic acid as the desorbing agents. For this, the dye loaded carbon particles, after filtration, were contacted with $50 \mathrm{~mL}$ of desorbing solutions for four hours and the extracted dye concentrations are found calorimetrically.

\section{Results and Discussion}

\section{Equilibrium studies}

The equilibrium adsorption data obtained are correlated to the following three isotherm equations: Freundlich, Langmuir and Redlich-Peterson. The Langmuir model assumes monolayer surface coverage on equivalent $\operatorname{sites}^{10}$, the Freundlich model, on the other hand, assumes a heterogeneous adsorption surface with sites that have different energies of adsorption and are not equally available. The Freundlich equation ${ }^{11}$ is more widely used but provides no information on the monolayer adsorption capacity in contrast to the Langmuir model. The Redlich-Peterson model ${ }^{12}$ is described as a combination of both the other models and is often used to describe equilibrium over a wide range of concentration.

$$
\begin{aligned}
\text { Freundlich } q_{e} & =x / m=K_{F} C_{e}^{(1 / n)} \\
\text { Langmuir } q_{e} & =K_{L} C_{e} /\left(1+b C_{e}\right)=q_{m} b C_{e} /\left(1+b C_{e}\right) \\
\text { Redlich-Peterson } q_{e} & =K_{R} C_{e} /\left(1+b_{R} C_{e}^{\beta}\right)
\end{aligned}
$$

The combined isotherm plots are shown in Figure 1. The individual isotherm shapes have been found from these plots and were labeled under Giles's classification. ${ }^{13}$ The sorption of $\mathrm{RB}$ is of $\mathrm{L} 1$ type while that of $\mathrm{MG}$ is that of the high affinity $\mathrm{H} 2$ type. The isotherm constants have been calculated and their values are presented in Table 2 along with their correlation coefficient values.

Two points are clear from Table 2. The first is that of the three isotherm models used it is the three-parameter Redlich-Peterson model that describes the equilibrium data with best accuracy (as inferred from the correlation coefficient values, $\mathrm{r}^{2}$ ). The second fact is the high adsorption capacity of the carbon towards MG. This is evident from the Langmuir monolayer capacity values (3.9438 for RB while 83.4063 for MG). The high capacity towards MG could be due to the small size of MG compared to RB. The small MG molecules can get access into even small pores while the relatively larger RB can't.

\section{pH Variation}

The effect of initial $\mathrm{pH}$ of external solutions on the adsorption extent of dyes are shown in Figure 2 [Operating conditions: for $\mathrm{RB}$ adsorption (initial concentration $=25 \mathrm{mg} / \mathrm{L}$ ) $0.50 \mathrm{~g} / 50 \mathrm{~mL}$ of TFC and for MG adsorption (initial concentration $=80 \mathrm{mg} / \mathrm{L}$ ) $0.1 \mathrm{~g} / 50 \mathrm{~mL}$ of TFC is used]. 


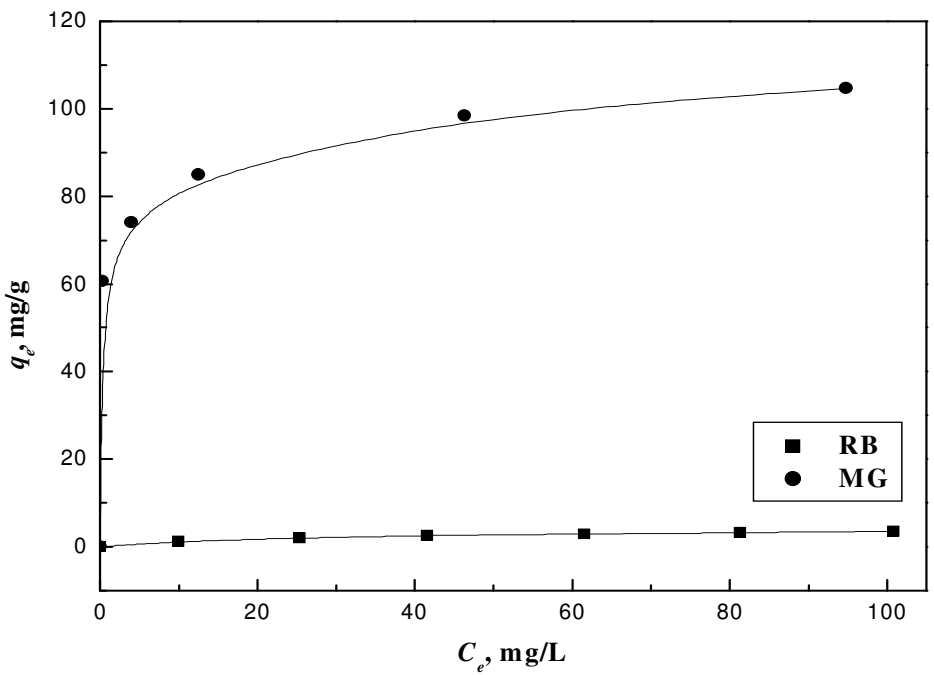

Figure 1. Adsorption of RB and MG on TFC

Table 2. Isotherm constants for adsorption of dyes at $30^{\circ} \mathrm{C}$

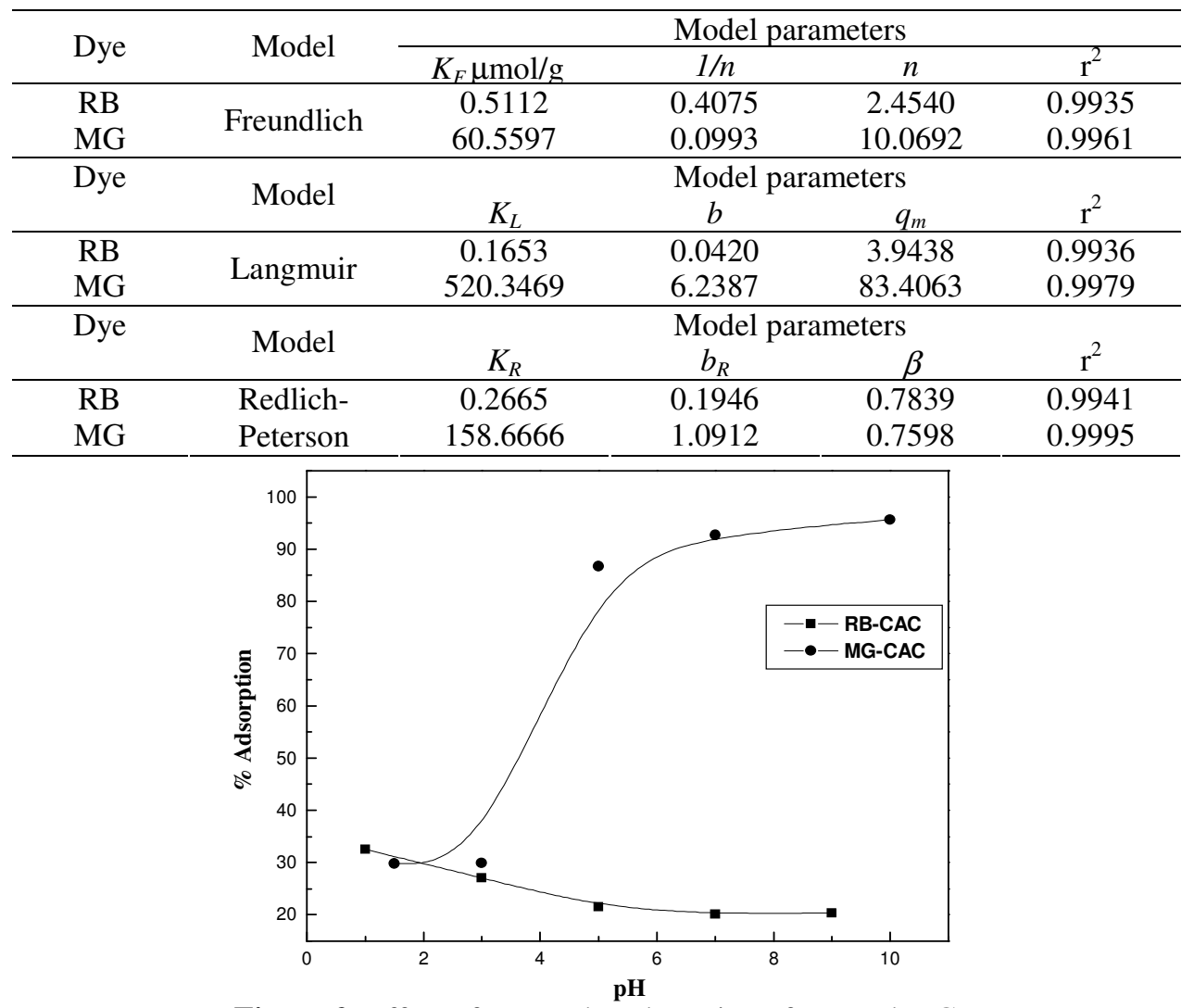

Figure 2. Effect of $\mathrm{pH}$ on the adsorption of $\mathrm{RB}$ and $\mathrm{MG}$ 
Though there are some discrepancies at pHs below 4.0 for RB adsorption, it is seen in general, that increasing solution $\mathrm{pH}$ increases the extent of dye removal. This trend can be explained as follows. Both the dyes selected for study are cationic dyes. When the solution $\mathrm{pH}$ is increasing, the adsorbents' surface will become more and more negative which will increase the affinity of the surface towards the positively charged dye molecules.

\section{Kinetics}

The kinetic curves for the adsorption of dyes are shown in Figure 3.

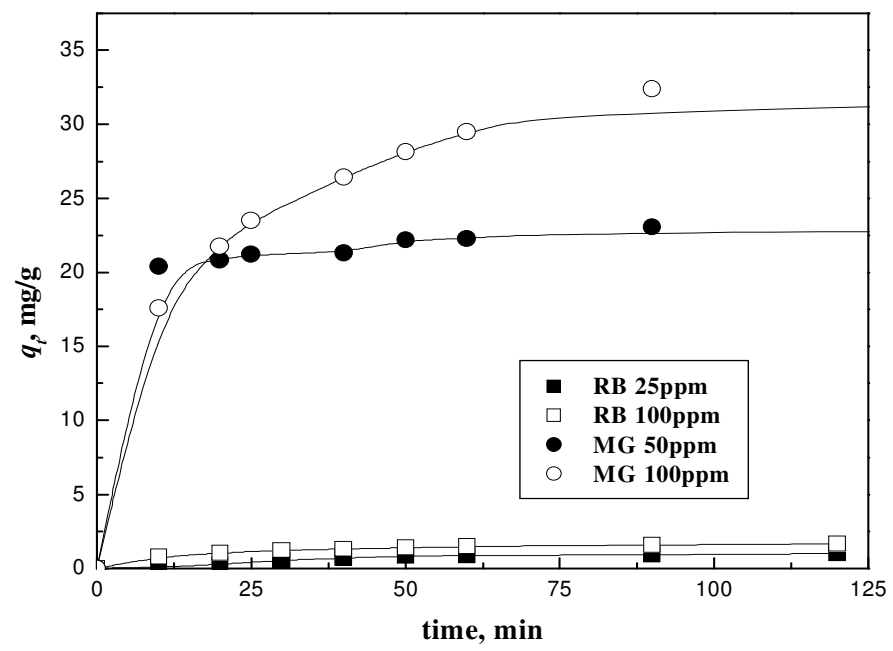

Figure 3. Kinetic curves for the adsorption of dyes on TFC

The kinetic data obtained were fitted to the following two kinetic models reported in the literature ${ }^{14,15}$

First order rate equation $\log \left(q_{e}-q_{t}\right)=\log q_{e(1)}-k_{l} t$

Second order rate equation $\quad t / q_{t}=(1 / h)+\left(1 / q_{e(2)}\right) t$

where, $q_{t}(\mathrm{mg} / \mathrm{g})$ is the amount adsorbed at time $t(\mathrm{~min}) ; q_{e}$, amount adsorbed at equilibrium $(\mathrm{mg} / \mathrm{g}) ; q_{e(1)}$, adsorption capacity predicted by the I order model $(\mathrm{mg} / \mathrm{g}) ; k_{l}$, first order rate constant $\left(\mathrm{min}^{-1}\right) ; h\left(=k_{2} / q_{e(2)}{ }^{2}\right)$, initial sorption rate $\left(\mathrm{mgg}^{-1} \mathrm{~min}^{-1}\right)$; and $q_{e(2)}$, adsorption capacity predicted by the II order model $(\mathrm{mg} / \mathrm{g})$.

The results of kinetic fittings and the parameters associated with each model along with the correlation coefficients are shown in Tables 3 and 4.

The high correlation coefficients and the good agreement between the theoretical $q_{e}$ and experimental $q_{e}$ values for the II order model suggest that the sorptions are better described by this model. Such a betterment of the II order model over I order model has been observed for many adsorption processes.

Table 3. Pseudo-first order parameters for adsorption of dyes at $30^{\circ} \mathrm{C}$

\begin{tabular}{|c|c|c|c|c|c|}
\hline \multirow{2}{*}{ Dye } & \multirow{2}{*}{$C_{i} \mathrm{mg} / \mathrm{L}$} & \multicolumn{2}{|c|}{ Equilibrium uptake $\mathrm{mg} / \mathrm{g}$} & \multirow{2}{*}{$\begin{array}{l}\text { Pseudo- first order rate } \\
\text { constant } k_{l}, \min ^{-1}\end{array}$} & \multirow{2}{*}{$r^{2}$} \\
\hline & & $q_{e(I)}$ & $q_{e(e x p)}$ & & \\
\hline \multirow[t]{2}{*}{$\overline{\mathrm{RB}}$} & 25 & 1.2618 & 1.003 & 0.0152 & 0.9900 \\
\hline & 100 & 1.0777 & 1.665 & 0.0125 & 0.9982 \\
\hline \multirow[t]{2}{*}{ MG } & 50 & 4.6441 & 24.340 & 0.0061 & 0.9848 \\
\hline & 100 & 21.8072 & 34.41 & 0.0112 & 0.9980 \\
\hline
\end{tabular}


Assuming the dye molecules as ions, attempts were made to study whether the (ionic) adsorption is film-diffusion controlled or particle-diffusion controlled following the methodology of Boyd ${ }^{16}$ and Reichenberg ${ }^{17}$ The sorption kinetics is represented by the following equation:

$$
F=1-6 / \pi^{2} \sum_{n=1}^{\infty} 1 / n^{2} \exp \left(-n^{2} B t\right)
$$

where, $B\left(=D_{i} \pi^{2} r^{2}\right)$ is a time constant; $F$ is the fractional attainment of equilibrium at time $t ; D_{i}$ is the effective diffusion coefficient of the ions in the adsorbent phase; $r$ is adsorbent particle radius and $\mathrm{n}(=1,2,3, \ldots)$ are the integers defining the infinite series solution obtained by a Fourier type of analysis. $B t$ values can be derived for each $F$ value by the use of Reichenberg's table. ${ }^{17}$ A plot of $t$ versus $B t$ is used to find whether the process is film or particle diffusion controlled. The $t$ versus Bt plots are presented in Figure 4.

Table 4. Pseudo-second order parameters for adsorption of dyes at $30^{\circ} \mathrm{C}$

\begin{tabular}{ccccccc}
\hline \multirow{2}{*}{ Dye } & \multicolumn{5}{c}{$C_{i} \mathrm{mg} / \mathrm{L}$} & \multicolumn{2}{c}{$\begin{array}{c}\text { Equilibrium uptake, } \\
\mathrm{mg} / \mathrm{g}\end{array}$} & $\begin{array}{c}\text { Pseudo- second order } \\
\text { rate constant, } k_{2} \mathrm{gmg}^{-}\end{array}$ & $\begin{array}{c}\text { Initial sorption rate, } h \\
\mathrm{mgg}^{-1} \mathrm{~min}^{-1}\end{array}$ & $\mathrm{r}^{2}$ \\
\cline { 3 - 5 } & & $q_{e(2)}$ & $q_{\text {e(exp) }}$ & min $^{-1}$ & 0.0397 & 0.9964 \\
RB & 25 & 1.2845 & 1.003 & 0.0241 & 0.1240 & 0.9996 \\
& 100 & 1.8556 & 1.665 & 0.0360 & 8.8574 & 0.9995 \\
MG & 50 & 23.4742 & 24.340 & 0.0161 & 3.2510 & 1.0000 \\
\hline
\end{tabular}

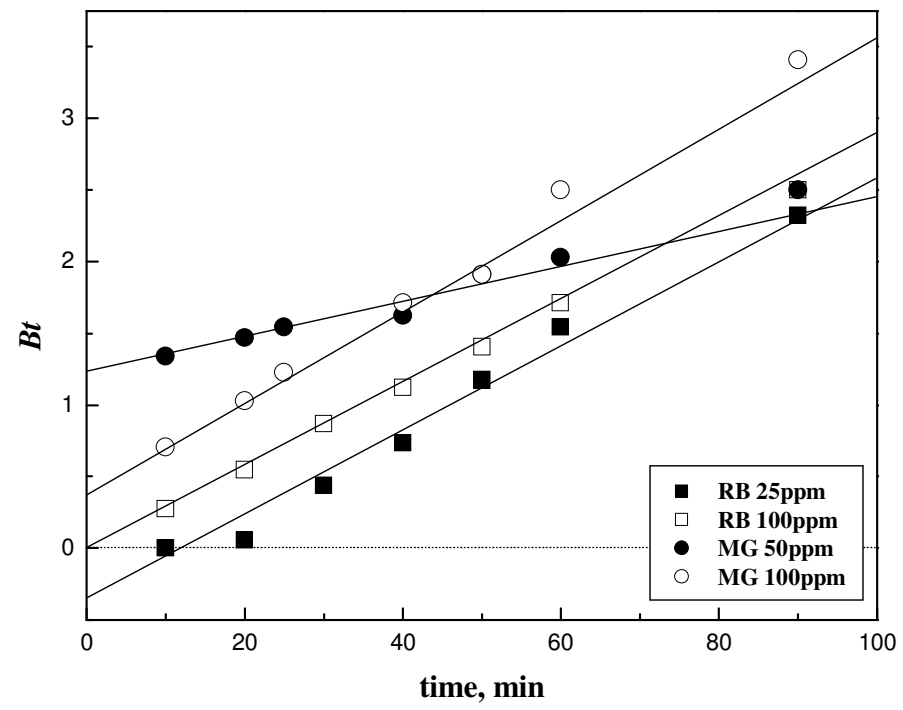

Figure 4. $t$ versus $B t$ plots for the adsorption of dyes at different concentrations

It is seen from figure 4 that the lower concentrations plots do not pass near the origin while for higher concentrations the lines cut the $\mathrm{x}$-axis near the origin indicating that pore or particle diffusion of the dyes is rate determining at higher concentrations. On the other hand, film diffusions may be controlling the overall rate at low concentrations. The effective pore diffusion coefficients evaluated are presented in Table 5.

\section{Effect of Temperature}

Increase in reaction temperature lead to increase in the extent of adsorption of both dyes. Isotherm parameters evaluated at the higher temperatures are given in Tables 6 and 7. 
Table 5. Effective pore diffusion coefficients controlling the rate of adsorption at different initial concentrations of dyes on TFC

\begin{tabular}{ccccc}
\hline Dye & $\begin{array}{c}C_{i} \\
\mathrm{mg} / \mathrm{L}\end{array}$ & $\begin{array}{c}B \\
\mathrm{~min}^{-1}\end{array}$ & $D_{i} \times 10^{-5} \mathrm{~cm}^{2} \mathrm{~min}^{-1}$ & $\mathrm{r}^{2}$ \\
\hline RB & 25 & 0.0311 & 3.1511 & 0.9931 \\
& 100 & 0.0280 & 2.8370 & 0.9997 \\
MG & 50 & 0.0146 & 1.4793 & 0.9910 \\
& 100 & 0.0340 & 3.4449 & 0.9969 \\
\hline
\end{tabular}

Table 6. Isotherm constants for adsorption of Dyes at $45^{\circ} \mathrm{C}$

\begin{tabular}{|c|c|c|c|c|c|}
\hline \multirow{2}{*}{ Dye } & \multirow{2}{*}{ Model } & \multicolumn{4}{|c|}{ Model parameters } \\
\hline & & $K_{F} \mu \mathrm{mol} / \mathrm{g}$ & $1 / n$ & $n$ & $\mathrm{r}^{2}$ \\
\hline \multirow{2}{*}{$\begin{array}{l}\text { RB } \\
\text { MG }\end{array}$} & \multirow{2}{*}{ Freundlich } & 0.9006 & 0.3350 & 2.9851 & 0.9932 \\
\hline & & 69.9816 & 0.1118 & 8.9445 & 0.9861 \\
\hline \multirow{2}{*}{ Dye } & \multirow{2}{*}{ Model } & \multicolumn{4}{|c|}{ Model parameters } \\
\hline & & $K_{L}$ & $b$ & $q_{m}$ & $\mathrm{r}^{2}$ \\
\hline \multirow{2}{*}{$\begin{array}{l}\text { RB } \\
\text { MG }\end{array}$} & \multirow{2}{*}{ Langmuir } & 0.2980 & 0.0652 & 4.5706 & 0.9938 \\
\hline & & - & - & - & - \\
\hline \multirow{2}{*}{ Dye } & \multirow{2}{*}{ Model } & \multicolumn{4}{|c|}{ Model parameters } \\
\hline & & $K_{R}$ & $b_{R}$ & $\beta$ & $r^{2}$ \\
\hline $\mathrm{RB}$ & Redlich- & 0.5132 & 0.2570 & 0.8261 & 0.9998 \\
\hline MG & Peterson & $1.44 \times 10^{8}$ & $2.066 \times 10^{7}$ & 0.8882 & 0.9891 \\
\hline
\end{tabular}

Table 7. Isotherm constants for adsorption of Dyes at $60^{\circ} \mathrm{C}$

\begin{tabular}{|c|c|c|c|c|c|}
\hline \multirow{2}{*}{ Dye } & \multirow{2}{*}{ Model } & \multicolumn{4}{|c|}{ Model parameters } \\
\hline & & $K_{F} \mu \mathrm{mol} / \mathrm{g}$ & $1 / n$ & $n$ & $\mathrm{r}^{2}$ \\
\hline \multirow{2}{*}{$\begin{array}{l}\text { RB } \\
\text { MG }\end{array}$} & \multirow{2}{*}{ Freundlich } & 0.9006 & 0.3350 & 2.9851 & 0.9932 \\
\hline & & 75.3823 & 0.1125 & 8.8889 & 0.9950 \\
\hline \multirow{2}{*}{ Dye } & \multirow{2}{*}{ Model } & \multicolumn{4}{|c|}{ Model parameters } \\
\hline & & $K_{L}$ & $b$ & $q_{m}$ & $r^{2}$ \\
\hline $\mathrm{RB}$ & \multirow{2}{*}{ Langmuir } & 0.7949 & 0.1738 & 4.5736 & 0.9497 \\
\hline MG & & - & - & - & - \\
\hline \multirow{2}{*}{ Dye } & \multirow{2}{*}{ Model } & \multicolumn{4}{|c|}{ Model parameters } \\
\hline & & $K_{R}$ & $b_{R}$ & $\beta$ & $\mathrm{r}^{2}$ \\
\hline $\mathrm{RB}$ & Redlich-Peterson & 0.3428 & 0.0065 & 1.2493 & 0.9956 \\
\hline MG & Keanin-reterson & - & - & - & - \\
\hline
\end{tabular}

van't Hoff equation (equation 7) was used to calculate the thermodynamic parameters involved in the sorption processes.

$$
\log \mathrm{Kc}=[\Delta \mathrm{S} / 2.303 \mathrm{R}]-[\Delta \mathrm{H} / 2.303 \mathrm{RT}]
$$

where $\mathrm{K}_{\mathrm{C}}$ is the equilibrium constant for the distribution of dyes between the liquid and solid phases; $\mathrm{T}$ is absolute temperature, ${ }^{\circ} \mathrm{K}$ and $\mathrm{R}$ the gas constant. Van't Hoff plots were constructed for each system and $\Delta \mathrm{H}$ and $\Delta \mathrm{S}$ were calculated from the slope and intercept of the plots, respectively (Table 8) 
Table 8. Thermodynamic parameters for adsorption of dyes on TFC

\begin{tabular}{ccccccc}
\hline \multirow{2}{*}{ Dye $C_{i} \mathrm{mg} / \mathrm{L}$} & \multicolumn{3}{c}{$-\Delta \mathrm{G} \mathrm{KJ} \mathrm{mol}^{-1}$} & \multirow{2}{*}{$\Delta \mathrm{H} \mathrm{KJmol}^{-1}$} & \multirow{2}{*}{$\Delta \mathrm{S} \mathrm{JK}^{-1} \mathrm{~mol}^{-1}$} \\
\cline { 2 - 5 } & 10 & 0.6208 & 2.1775 & 5.0257 & 53.2358 & 145.5049 \\
& 20 & -0.6229 & 0.5894 & 2.0551 & 27.6334 & 89.0170 \\
\multirow{4}{*}{$\mathrm{RB}$} & 30 & -1.1657 & -0.4168 & 0.1861 & 14.8454 & 45.2236 \\
& 40 & -1.9075 & -1.1660 & -0.6572 & 14.5771 & 41.9284 \\
& 50 & -2.3742 & -1.8033 & -1.3042 & 13.1957 & 35.7496 \\
& 60 & -2.6854 & -2.2633 & -1.7643 & 11.9778 & 30.6278 \\
\hline \multirow{4}{*}{$\mathrm{MG}$} & 40 & 15.1381 & 17.6174 & 19.9189 & 33.1843 & 159.5780 \\
& 50 & 9.0901 & 10.3247 & 12.8949 & 29.1212 & 125.4482 \\
& 60 & 6.5676 & 8.1603 & 9.9240 & 27.3085 & 111.7217 \\
& 80 & 3.6487 & 4.7314 & 5.9996 & 20.0680 & 78.1816 \\
& 100 & 1.9945 & 3.0143 & 3.7557 & 15.8435 & 59.0115 \\
\hline
\end{tabular}

The negative values of $\Delta \mathrm{G}$ obtained for the adsorptions reflect the spontaneity. The positive values of $\Delta \mathrm{H}$ indicate the endothermic nature and the positive values of $\Delta \mathrm{S}$ indicate increased randomness at the interface. The magnitudes of $\Delta \mathrm{S}$ for the adsorption of dyes are much higher than those of metal ions. This could be due to the size of the dye molecules. A single dye molecule displaces a lot of water molecules from the adsorbent surface, as it is very large in size compared to water molecules.

\section{Desorption Studies}

The results of desorption studies are presented in Table 9. Dilute acetic acid was able to desorb the adsorbed dyes to the greatest extent. These results strongly points that the dyes are chemisorbed on the adsorbent.

Table 9. Desorption of dyes

\begin{tabular}{cccc}
\hline \multirow{2}{*}{ Dye } & \multicolumn{3}{c}{ \% Desorption with } \\
\cline { 2 - 4 } & Water & $0.1 \mathrm{M} \mathrm{AcOH}$ & $0.1 \mathrm{M} \mathrm{HCl}$ \\
\hline RB & 35.01 & 79.45 & 55.87 \\
MG & 40.25 & 83.19 & 68.15 \\
\hline
\end{tabular}

\section{Conclusions}

The work described has shown that direct carbonization of tamarind fruit shells can be used as a means of preparation of activated carbon that can be successfully used for the removal of cationic dyes like rhodamine B and malachite green. The three-parameter RedlichPeteroson model was the best among the three isotherm models studied in correctly predicting the equilibrium adsorption data. The kinetics of the $\mathrm{pH}$ dependant sorptions were found to be film-diffusion controlled at low dye concentrations and particle diffusion controlled at high dye concentrations. Temperature variation studies indicated that the sorptions are endothermic. Dilute acetic acid can be successfully used for the desorption of adsorbed dye molecules.

\section{References}

1. Mittal A K and Venkobachar C, Indian J Environ Health, 1989, 31, 105-111.

2. Nakamura T, Tokimoto T, Tamura T, Kawaski N and Tanada S, J Health Sci., 2003, 49(6), 520-523. 
3. Choi J H, Shin W S, Lee W S, Joo D J, Lee J D and Choi S J, Environ Technol., 2001, 22, 1025-1033.

4. Wu J and Wang T, Water Res., 2001, 35, 1093-1099.

5. Buckley C A, Water Sci Technol., 1992, 22, 265-274.

6. $\quad$ Lin S H and Peng C F, Water Res., 1996, 30, 587-592.

7. $\quad$ Aplin R and Wait T D. Water Sci Technol., 2000, 42, 345-354.

8. Henderson A L, Schmitt T C, Heinze T M and Cerniglia C E, Appl Environ Microbiol., 1997, 63, 4099-4101.

9. Lambert S D, Water Technol., 1997, 36, 173-180.

10. Langmuir I, J Am Chem Soc., 1918, 40, 1361-1403.

11. Freundlich H, Zeitschrift fü ur Physikalische, Chemie 1907, 57, 385-470.

12. Redlich O, Peterson D L, J Phys Chem., 1959, 63, 1024-1026.

13. Giles C H, MacEwan T H, Nakhwa S N and Smith D, J Chem Soc., 1960, 4, 3973-3993.

14. Ho Y S and McKay G, I Chem E., B, 1998, 76, 332-340.

15. Ho Y S and McKay G, Process Biochem, 1999, 34, 451-465.

16. Boyd G E, Adamson A W and Myers L S Jr, J Am Chem Soc., 1947, 69, 2836-2848.

17. Reichenberg D, J Am Chem Soc., 1953, 75, 589-597. 


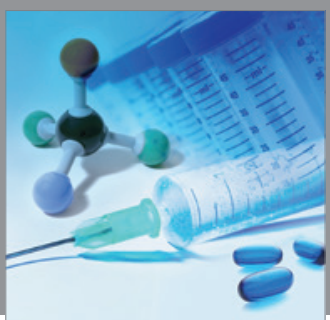

International Journal of

Medicinal Chemistry

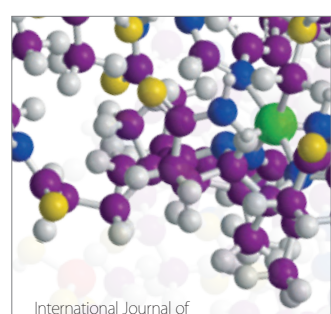

Carbohydrate Chemistry

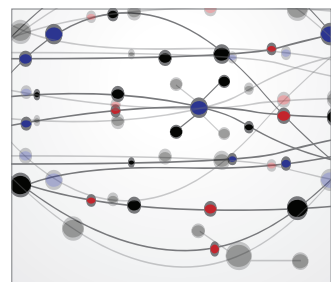

The Scientific World Journal
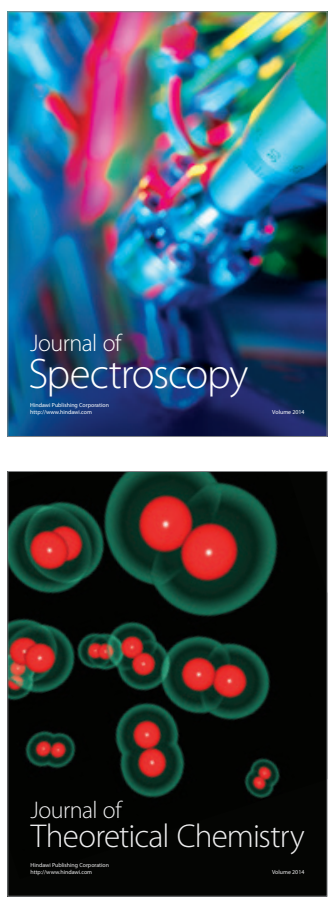
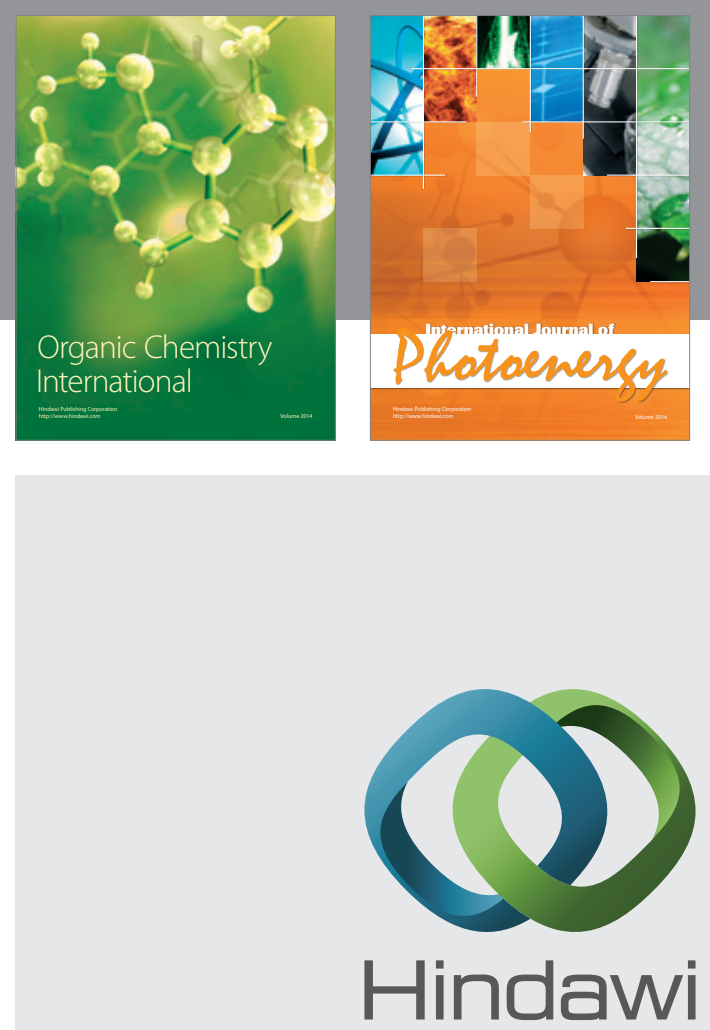

Submit your manuscripts at

http://www.hindawi.com
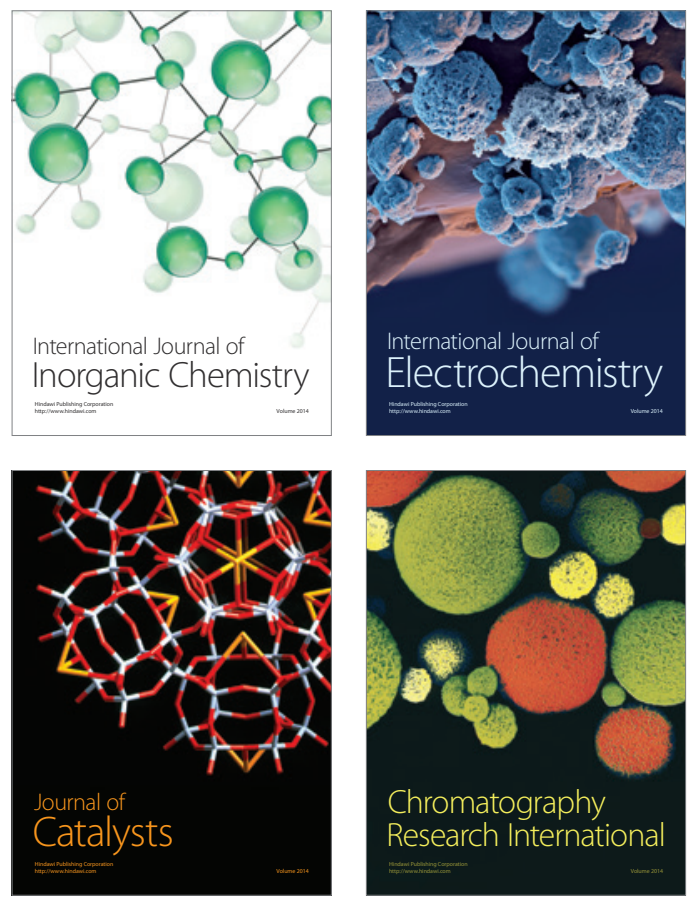
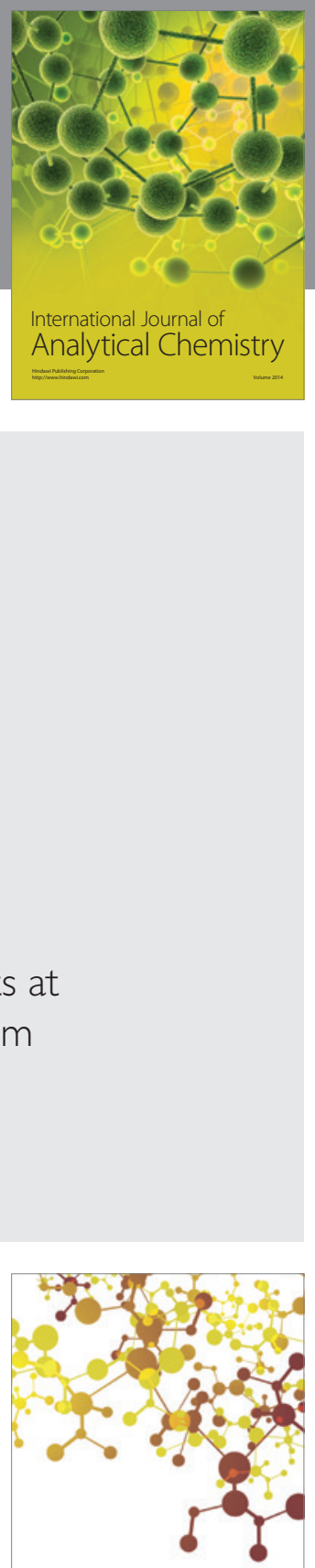

Journal of

Applied Chemistry
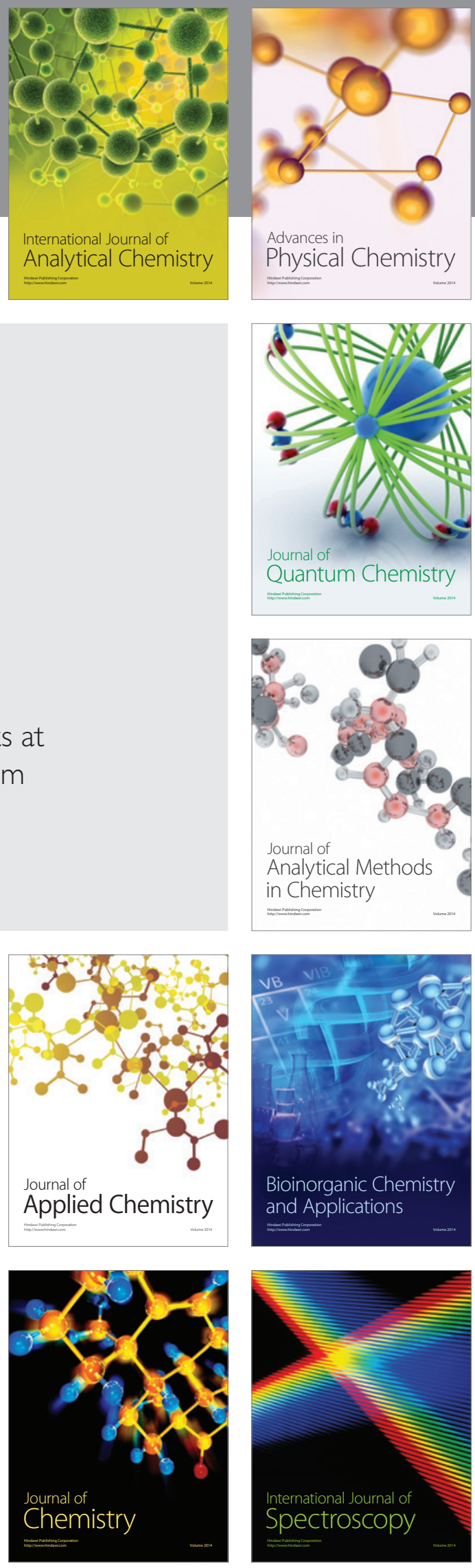